\title{
Plant respiration under low oxygen
}

\author{
Guillermo Toro $^{1 *}$, and Manuel Pinto ${ }^{2}$
}

\begin{abstract}
Respiration is an oxidative process controlled by three pathways: glycolysis, the tricarboxylic acid (TCA) cycle, and oxidative phosphorylation (OXPHOS). Respiratory metabolism is ubiquitous in all organisms, but with differences among each other. For example in plants, because their high plasticity, respiration involves metabolic pathways with unique characteristics. In this way, in order to avoid states of low energy availability, plants exhibit great flexibility to bypass conventional steps of glycolysis, TCA cycle, and OXPHOS. To understand the energetic link between these alternative pathways, it is important to know the growth, maintenance, and ion uptake components of the respiration in plants. Changes in these components have been reported when plants are subjected to stress, such as oxygen deficiency. This review analyzes the current knowledge on the metabolic and functional aspects of plant respiration, its components and its response to environmental changes.
\end{abstract}

Key words: Electron transport chain, hypoxia, Krebs cycle, maintenance respiration.

\section{INTRODUCTION}

Plants are autotrophic organisms able to use solar radiation to split water molecules $\left(\mathrm{H}_{2} \mathrm{O}\right)$ and reduce the carbon dioxide $\left(\mathrm{CO}_{2}\right)$ compounds that can finally be stored as insoluble polysaccharides (starch) or used directly in the synthesis of other compounds. In plants glucose is the main substrate for respiration. This process oxidizes carbohydrates through two principal pathways: glycolysis and the tricarboxylic acid (TCA) cycle. The products from these two pathways are $\mathrm{CO}_{2}$ and the reduced compounds $\mathrm{NAD}(\mathrm{P}) \mathrm{H}_{2}$ and $\mathrm{FADH}_{2}$, which in turn are used for oxidative phosphorylation (OXPHOS), transferring their electrons to the terminal oxidase where $\mathrm{O}_{2}$ acts as the final electron acceptor, producing highenergy phosphate bonds (ATP) (Millar et al., 2011; van Dongen et al., 2011). ATP represents the most efficient way to obtain energy for the synthesis of biomolecules and to maintain cellular structures, transport photoassimilates, uptake ions, assimilate $\mathrm{N}$ and $\mathrm{S}$, regulate protein turnover and maintain electrochemical potential gradients across membranes in cells (Amthor, 2000).

Plant respiration has been widely studied, but despite this effort and the available new technologies,

${ }^{1}$ Centro de Estudios Avanzados en Fruticultura (CEAF), Camino Las Parcelas 882, sector Los Choapinos, Rengo, Chile.

*Corresponding author (guillermotoro@gmail.com).

${ }^{2}$ Instituto de Investigaciones Agropecuarias, INIA La Platina, Santa

Rosa 11610, La Pintana, Santiago, Chile.

Received: 20 December 2014.

Accepted: 7 May 2015.

doi:10.4067/S0718-58392015000300007 its mechanisms of regulation and control still require further elucidation. For instance, studies on the enzymatic functionality of glycolysis have determined the importance of phosphoglucomutase (PGM) in starch formation processes in both heterotrophic (root and seed) and autotrophic tissues as well as the role of hexokinases (HXK) and other enzymes such as the glucose signaling network (Sheen, 2014). Regarding the TCA cycle, some progress has been made in understanding how alternative pathways involving $\gamma$-aminobutyric acid (GABA) and the glyoxylate cycle operate, with special attention given to changes in the optimal conditions, in order to show the high level of plasticity in the response of the TCA cycle to environmental changes (Sweetlove et al., 2010). More details will be given in another section below.

On the other hand, research has been directed at finding new non-phosphorylates or alternative pathways for OXPHOS that allow energy to be dissipated. Alternative oxidase $(\mathrm{AOX})$ is a protein associated with the inner mitochondrial membrane, it has been shown to be induced by a series of stress factors such as high and low temperatures, drought, and nutrient deficiency, among others (Moore et al., 2002). Furthermore, alternatives have also been found to the maintenance of the proton gradient in the mitochondrial matrix, which is performed through uncoupled proteins (UCP) that enables flows of protons to enter the matrix independent of ATP synthesis (ArnholdtSchmitt et al., 2006). In turn, UCP would participate in the reduction of reactive oxygen species (ROS), a function also contributed to by AOX (Smith et al., 2004).

Respiration plays an important role in acclimation to different types of abiotic stress (water, temperature, 
photoinhibition, salinity, nutrient deficiencies, and hypoxia/anoxia, etc.), therefore many studies have focused on understanding the function, organization, and regulation of respiratory metabolism under unfavorable environments. These stresses usually result in changes in the energy requirements of plants, which in turn induce changes in respiratory metabolism as well as in other enzymes, electron transport, and redox gradient formation, among others. One important stress that affects respiration is partial deficiency (hypoxia) or absolute absence (anoxia) of oxygen. For instance, under hypoxic conditions alanine creates a link to glycolysis (de Sousa and Sodek, 2003). Moreover, under anoxia, fermentative lactate and ethanol pathways are activated and the rate of ethanol synthesis rises more than 5 fold as compared to normal conditions (Mancuso and Marras, 2006).

Because of this concern, the objective of this review was to analyze the state of the art of plant respiration, both in terms of metabolism and from a functional point of view. For this reason, in the first part of this review, a comparative analysis of the major metabolic pathways of aerobic respiration in animals and plants is performed. Then, after analyzing recent advances in knowledge about the functionality of respiration in plants beyond its traditional role as an energy generating process, we discuss in particular its role in the synthesis of new compounds and in the maintenance of molecules and structures. Consideration is particularly given to functions under different kinds of stress. Finally, the response of different parts of the anaerobic respiration system to oxygen restrictions and the functionality of alternative metabolic pathways activated in plants when oxygen is restricted (i.e. during hypoxia) are discussed.

\section{Overview of plant respiration}

Respiration involves the participation of different processes responsible for the oxidation of glucose molecules for energy and $\mathrm{C}$ structures, either in the presence (aerobic) (Millar et al., 2011; van Dongen et al., 2011) or absence (anaerobic) of oxygen (Gupta et al., 2009). In the latter case, the most affected organ is the root, inducing partial oxidation strategies of substrates in order to continue to generate energy without oxygen $\left(\mathrm{O}_{2}\right)$. These strategies are called fermentation, which differentiate themselves by their end products: ethanol, lactic acid and alanine (Sousa and Sodek, 2002).

In the presence of $\mathrm{O}_{2}$, substrates are completely oxidized to $\mathrm{CO}_{2}$ and $\mathrm{H}_{2} \mathrm{O}$ (van Dongen et al., 2011). This is done through three metabolic processes: glycolysis, the TCA cycle and the OXPHOS (Fernie et al., 2004). To these is added a fourth process; transport of the products of respiration. This corresponds to the movement of substrates and cofactors to facilitate the release of products throughout the cell (Millar et al., 2011). The operation of these processes is the most efficient way to obtain energy from complete oxidation of hydrocarbon substrates, both in plants and animals (Plaxton, 1996).

It has been reported that there are differences in respiration according to species and plant tissue (Millar et al., 2011); for example, spinach leaf respiration is preferably performed at night, because during the day it is inactivated at low solar radiation intensities $(10-50 \mu \mathrm{mol}$ $\mathrm{m}^{-2} \mathrm{~s}^{-1}$ ) (Atkin et al., 1998), presumably cause excess ATP from photosynthesis in chloroplasts (Atkin et al., 2004). However, for many years the effects of radiation on leaf respiration were studied without considering the effect of temperature. Thus, a study in eucalyptus plants showed that leaf respiration is highly dependent on both radiation and temperature, showing a high degree of inhibition of respiration at high temperatures and high radiation levels, which reduces the $\mathrm{CO}_{2}$ ratio (provided by photosynthesis) that is respired (Atkin et al., 2000).

Likewise, root respiration can be altered by a variety of factors such as temperature (Rachmilevitch et al., 2006), salinity (Bernstein et al., 2013), heavy metals (Moyen and Roblin, 2013), drought (Jiménez et al., 2013), waterlogging and flooding (Liao and Lin, 2001); however, the availability of $\mathrm{O}_{2}$ is what most affects root respiration (Gupta et al., 2009). This factor is key in respiration metabolism, because oxygen is the final electron acceptor in OXPHOS (Moller, 2001). Most of the energy (ATP) produced by root respiration is used for processes such as growth (van Iersel and Seymour, 2000; Thongo M'Bou et al., 2010), nitrate reduction, symbiotic $\mathrm{N}$ fixation (in legumes), the absorption of nitrate and other ions absorption by the roots (Poorter et al., 1991), protein turnover (De Visser et al., 1992; Bouma et al., 1994; Scheurwater et al., 2000), maintenance of the ion gradient and membrane potential (Veen, 1980; Bouma and De Visser, 1993) and waste mechanisms and production of heat through alternative pathways (Cannell and Thornley, 2000).

\section{Glycolysis in plants}

Glycolysis is an anaerobic pathway responsible for oxidizing sucrose (glucose in animals) to generate ATP, a reductant (NADH) and pyruvate (Millar et al., 2011; van Dongen et al., 2011). The universality of glycolysis is associated with its importance in adaptations to different environmental stressors, such as nutritional stress, temperature, drought, and anoxia, among others (Plaxton, 1996). In general, the transformation of glucose to pyruvate is performed through a series of reactions catalyzed by numerous enzymes (Figure 1) (Plaxton, 1996; van Dongen et al., 2011), which not only act as catalysts and energy metabolism regulators (CamachoPereira et al., 2009), but also as signal transducers in response to changes in the environment. For instance, it has been observed that the activity level of hexokinase (HXK) would correspond to a key component in the sugar signal detection. For example, it was determined that HXK (AtHXK1) regulates the signaling levels of sugar 


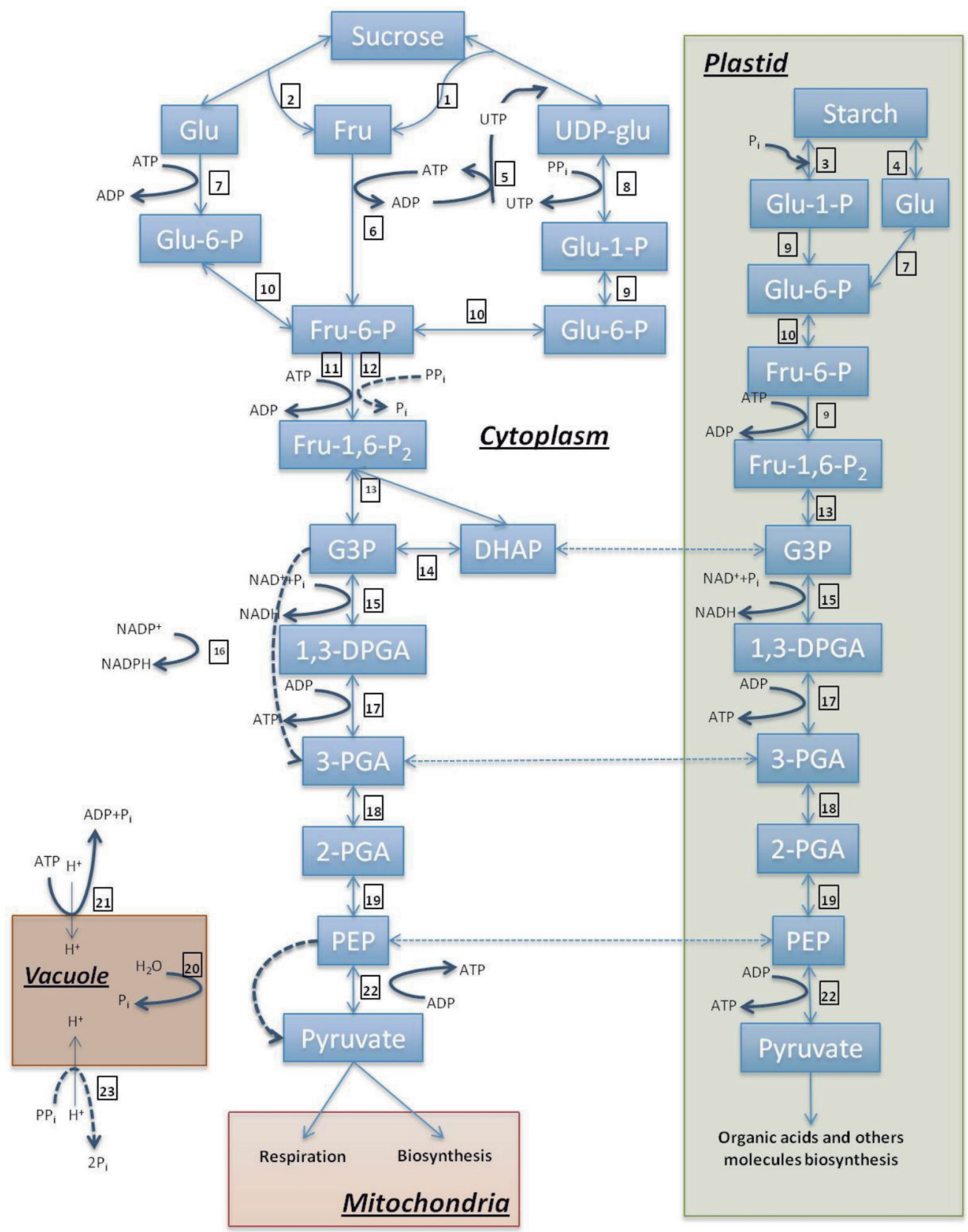

Source: Author based on Plaxton (1996) and Plaxton and Podestá (2006).

Enzymes involved in each reaction are as follows: 1) sucrose synthase, 2) invertase, 3) phosphorilase, 4) $\alpha$ and $\beta$-amylase, 5) NDP kinase, 6) fructokinase,

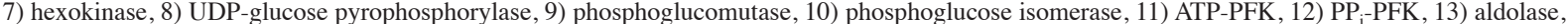
14) triose phosphate, 15) and 16) glyceraldehyde-3-phosphate phosphorylated and non-phosphorylated, respectively, 17) phosphoglycerate kinase, 18) phosphoglyceromutase, 19) enolase, 20) PEP phosphatase, 21) $\mathrm{H}^{+}$-ATPasa, 22) piruvate kinase, and 23) $\mathrm{H}^{+}$-PP $\mathrm{isa}_{\mathrm{i}}$.

Figure 1. Schematic representation of the glycolysis pathway and alternatives in vegetables. Continuous line represents glycolytic flux and broken lines represent alternatives.

in Arabidopsis gin2 mutants under different lighting conditions. Normal growth was observed in control plants; however, in mutant plants ( $\operatorname{gin} 2 / h x k 1)$, growth was inhibited due to a reduction in cell expansion (Moore et al., 2003).
In turn, HXK activity in plants is related to the link between glycolysis and programmed cell death (apoptosis). Briefly, mitochondrial pathways of apoptosis are initiated by mitochondrial cytochrome $c$ release (high control point of apoptosis initiation) into the cytoplasm 
through pores in the mitochondrial permeability transition (MPT) in response to some stress (Kim et al., 2006). HXK is an integral component of MPT, through its interaction with porins (VDAC, Voltage-Dependent Anion Channel). When HXK binds to VDAC it interferes with the opening of MPT, inhibiting the release of cytochrome $c$ into the cytoplasm and hence inhibiting apoptosis (Kim et al., 2006).

In animals, apoptotic activity has been attributed to the action of nuclear glyceraldehyde-3-phosphate dehydrogenase (GAPDH) on cultured neurons. Moreover, it has been observed that HXK mediates the signaling of sugars on the ABA pathway. The ginl mutant is allelic to $a b a$, which has been found to act on an enzyme that catalyses the last step in ABA biosynthesis, indicating that HXK level mediates signaling by the ABA pathway (Rolland et al., 2002). In addition, protective functions against ROS have also been attributed to a mitochondrial HXK through the generation of ADP for OXPHOS, avoiding limitations in the synthesis of ATP during respiration and facilitating the release of hydrogen peroxide (Camacho-Pereira et al., 2009). While HXK is found in the mitochondria, there is also evidence to indicate the presence of HXK in the cell nucleus (Kim et al., 2006). This would indicate that HXK might be controlled at the level of glycolytic gene expression.

Although each enzyme involved in the glycolytic flux corresponds to a critical control point in respiration, it was observed that altering the activities of these enzymes caused only minor changes in respiration rates (Hajirezaei et al., 2006; Oliver et al., 2008). This indicates that there are other key points in the regulation of respiration. Studies in different organisms (bacteria and mammals) show that one of the key sites of regulation and control of respiration is at the level of pyruvate kinase (PK), which catalyzes the final reaction in the pathway using ADP and phosphoenolpyruvate (PEP) for ATP and pyruvate (Teusink et al., 2000). Likewise, in plants the situation is complex because there are various isoforms of the same enzymes, such as PK (Plaxton and Podestá, 2006).

Unlike other organisms, glycolysis in plants can be carried out in two different subcellular compartments, in the cytoplasm and plastids (chloroplast and amyloplast). This makes it difficult to analyze and understand, because it involves interactions and connectivity through highly selective transporters, together with the interactions of about 23 different enzymes (Plaxton, 1996; MuñozBertomeu et al., 2010).

In animal cells studies have paid special attention to the spatial organization of glycolysis, because the physical concentrations of glycolytic enzymes may be associated with sites with high demand for ATP (Lu et al., 2001; Giegé et al., 2003) or other intermediates of glycolysis (Giegé et al., 2003; Fernie et al., 2004). A study in Arabidopsis established that the enzymes HXK, GADPH, and phosphofructokinase (PFK) were functionally associated with mitochondria (Giegé et al., 2003). Moreover, in bean (Phaseolus vulgaris L.) it was found that the enzymes 3-phosphoglycerate kinase (3PGK), GAPDH, and aldose are associated with the nuclei and cytoskeletons of leaf cells, while in corn, 3-PGK and aldose are only associated with the cytoskeleton (Azama et al., 2003). The glycolytic flux is controlled by a cascade of reactions in which there are checkpoints on the pathway, such as HXK and PK activity, which can control glycolysis not only at the mitochondrial level but also from a posttranslational level.

\section{Tricarboxylic acid cycle in plants}

The tricarboxylic (TCA) cycle, also called the Krebs cycle in honor of its discoverer, is an essential metabolic pathway. It is located in the mitochondrial matrix where, by the oxidation of organic $\mathrm{C}$ substrates (pyruvate and/or malate), it releases $\mathrm{CO}_{2}$ and provides reducing factors such as $\mathrm{NAD}(\mathrm{P}) \mathrm{H}$ and $\mathrm{FADH}_{2}$, which are primary substrates for the synthesis of ATP in the electron transport chain in mitochondria (Fernie et al., 2004; Mailloux et al., 2007; Sweetlove et al., 2010) (Figure 2). In turn, the TCA cycle provides $\mathrm{C}$ skeleton components and precursors for the biosynthesis of secondary metabolites such as terpenes, amino acids, and fatty acids, among others (Plaxton and Podestá, 2006; Sweetlove et al., 2010).

The TCA cycle begins with the reaction between acetyl CoA and oxaloacetate (OAA), yielding tricarboxylic acids that are oxidized and decarboxylated through a series of reactions in which $\mathrm{CO}_{2}$ molecules are released. At the end of the cycle, OAA is regenerated for re-condensation with acetyl CoA, restarting the cycle (Figure 2) (Mailloux et al., 2007; Sweetlove et al., 2010).

One of the main differences between the TCA cycle in plants and animals is the energy molecule generated during the processing of succinyl CoA to succinate. While ATP is produced by succinyl CoA synthase in plants, in animal cell there are two isoforms, GTP-specific succinyl CoA synthase (G-SCS) and ATP-specific succinyl CoA synthase, which generate guanosine-5'-triphosphate (GTP) from guanosine diphosphate (GDP) and ATP from ADP, respectively (Johnson et al., 1998).

Another feature associated with the TCA cycle in plants, but not found in other organisms, is related to the significant activity of NAD-dependent malic enzyme (NAD-ME) or malate oxidoreductase, responsible for catalyzing the oxidative decarboxylation of malate to pyruvate, finally allowing complete oxidation of malate (Jenner et al., 2001).

\section{Pathways associated with the TCA cycle in plants}

There are several alternative pathways in the TCA cycle, which give some flexibility against environmental changes or simply in the choice of which compounds to biosynthesize (Sweetlove et al., 2010). For instance, $\gamma$-aminobutyric acid (GABA) was long considered just a 


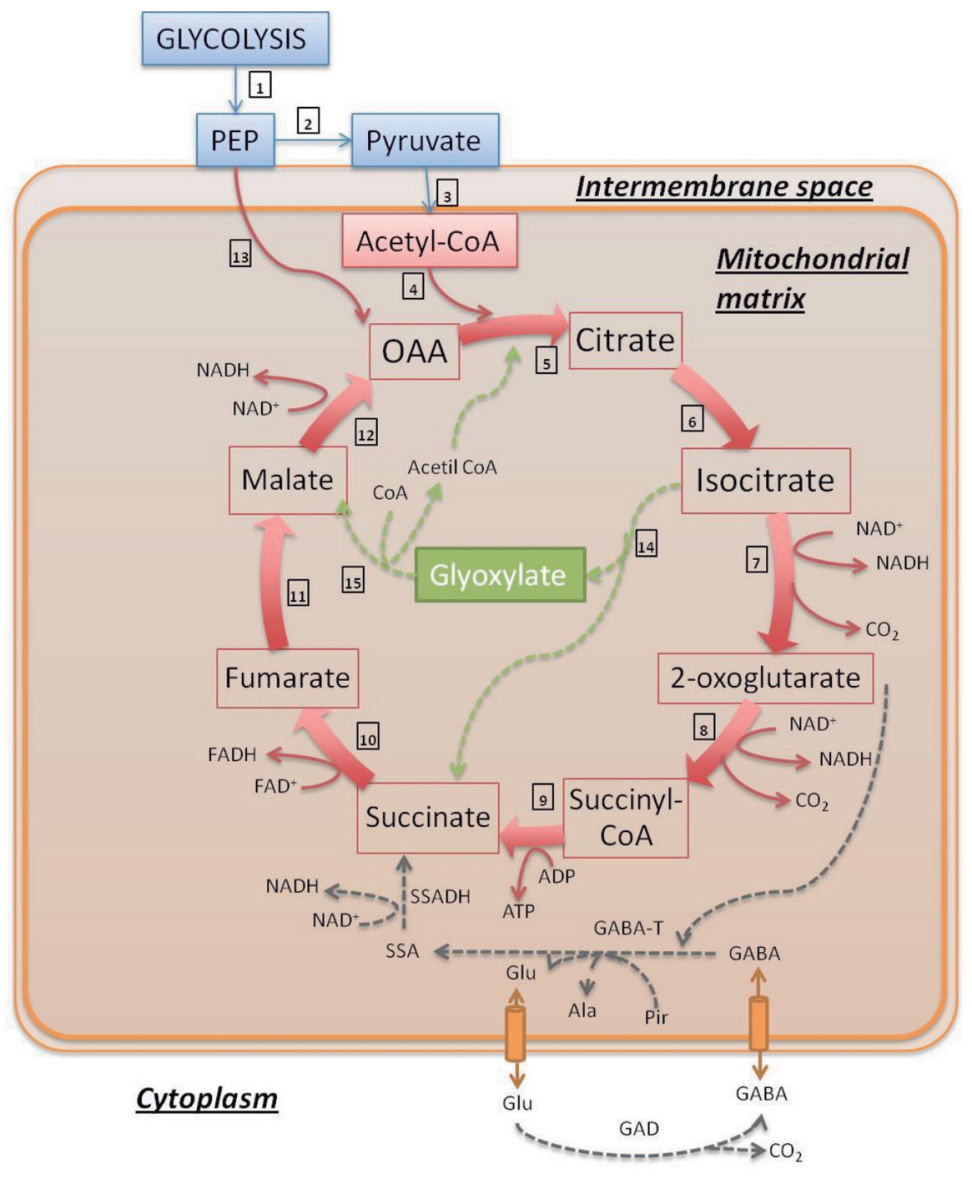

Source: Author based on Ryan et al. (2001) and Studart-Guimaraes et al. (2007).

PEP: Phosphoenolpyruvate, OAA: oxaloacetate, SSA: succinyl semialdehyde, SSADH: succinyl semialdehyde dehydrogenase, GABA: $\gamma$-aminobutyric acid, GABA-T: $\gamma$-aminobutyric acid transaminase, GAD: glutamate decarboxylase, Glu: glucose, Ala: alanine, Pir: pyruvate.

Enzymes involved in each reaction are as follows: 1) enolase, 2) pyruvate kinase, 3) pyruvate dehydrogenase, 4) coenzyme A, 5) citrate synthase, 6) aconitase, 7) isocitrate dehydrogenase, 8) 2-oxoglutarate dehydrogenase, 9) succinyl CoA synthase, 10) succinate dehydrogenase, 11) fumarase, 12) malate dehydrogenase, 13) phosphoenolpyruvate carboxylase, 14) isocitrate lyase, 15) malate synthase.

Figure 2. Schematic representation of tricarboxylic acid cycle (TCA) in plants. Red line: TCA cycle, green line: glyoxylate cycle, gray line: GABA route.

metabolite in plants with an unclear function; however, at present there is evidence to indicate that GABA plays a major role in $\mathrm{C}$ metabolism in response to stress (Bouché and Fromm, 2004). As shown in Figure 2, the GABA pathway is composed of three enzymes; glutamate decarboxylase (GAD), a cytoplasmic enzyme, and two mitochondrial enzymes called GABA transaminase and succinic-semialdehyde dehydrogenase (GABA-T and SSADH, respectively), present both in animals and plants (Bouché and Fromm, 2004; Sweetlove et al., 2010). In plants, it has been observed that GABA pathway responds quickly to environmental changes, e.g. it is stimulated under conditions of cold, salinity (Kinnersley and Turano, 2000), and anoxia (Aurisano et al., 1995). The role of GABA pathway in plants is still unclear because studies on this pathway are relatively new. However, it could be that GABA pathway is linked to many abiotic stress responses (Kinnersley and Turano, 2000). Unlike in plants, in mammals GABA clearly functions as a molecular neurotransmitter in the brain (Bouché and Fromm, 2004).

The glyoxylate cycle is another pathway associated with the TCA cycle in plants, defined as a modification of the TCA cycle (Figure 2) (Kornberg and Madsen, 1958). In turn, it has mainly been associated with lipid metabolism in seeds of oil plants (Eastmond and Graham, 2001). In general, the difference between glyoxylate cycle and TCA cycle is that the first avoids two points of decarboxylation and allows the generation of acetyl CoA through $\beta$-oxidation of fatty acids, giving rise to succinate, which is then incorporated into the mitochondria to generate OAA, which will go directly toward the synthesis of sucrose by gluconeogenesis (Eastmond and Graham, 2001). 
In oil seeds, the most important source of storage supply is lipids, which are used by the glyoxylate cycle to maintain growth and respiration of the seed. For example, in Arabidopsis seeds, lipids are stored in cotyledons that show marked $\mathrm{icl}$ and $\mathrm{mls}$ gene expression coding for isocitrate lyase and malate synthase, respectively, two key enzymes in the glyoxylate cycle (Eastmond and Graham, 2001). Light plays an important role in post germination growth, it being observed in mutants of Arabidopsis ( $\mathrm{icl}$ ) that a reduction in the activity of isocitrate lyase inhibits lipid breakdown and strongly reduces the growth of hypocotyl (Eastmond et al., 2000). In seedlings, the glyoxylate cycle plays a key role in growth because it is involved in lipid metabolism through the $\beta$-oxidation of fatty acids (Finkelstein and Gibson, 2002). This oxidation produces two-C units of acetyl-CoA capable of entering the glycolate cycle. Sugar (sucrose) is the ultimate product of this process, being the primary form in which reduced $\mathrm{C}$ is translocated from the cotyledons to the growing seedling tissues (Taiz and Zeiger, 1991).

\section{Oxidative phosphorylation in plants}

Oxidative phosphorylation (OXPHOS) (Figure 3) is the pathway in which oxidation of $\mathrm{NADH}$ and $\mathrm{FADH}_{2}$, which are produced during the TCA cycle, occurs. Here, the electrons resulting from oxidation are transferred through protein complexes (I, II, III, IV) inserted in the inner mitochondrial membrane ad on to $\mathrm{O}_{2}$, which acts as a final electron acceptor, finally reduced in the form of $\mathrm{H}_{2} \mathrm{O}$ (Bailey-Serres and Voesenek, 2008; Sweetlove et al., 2010). The electrochemical potential produced in

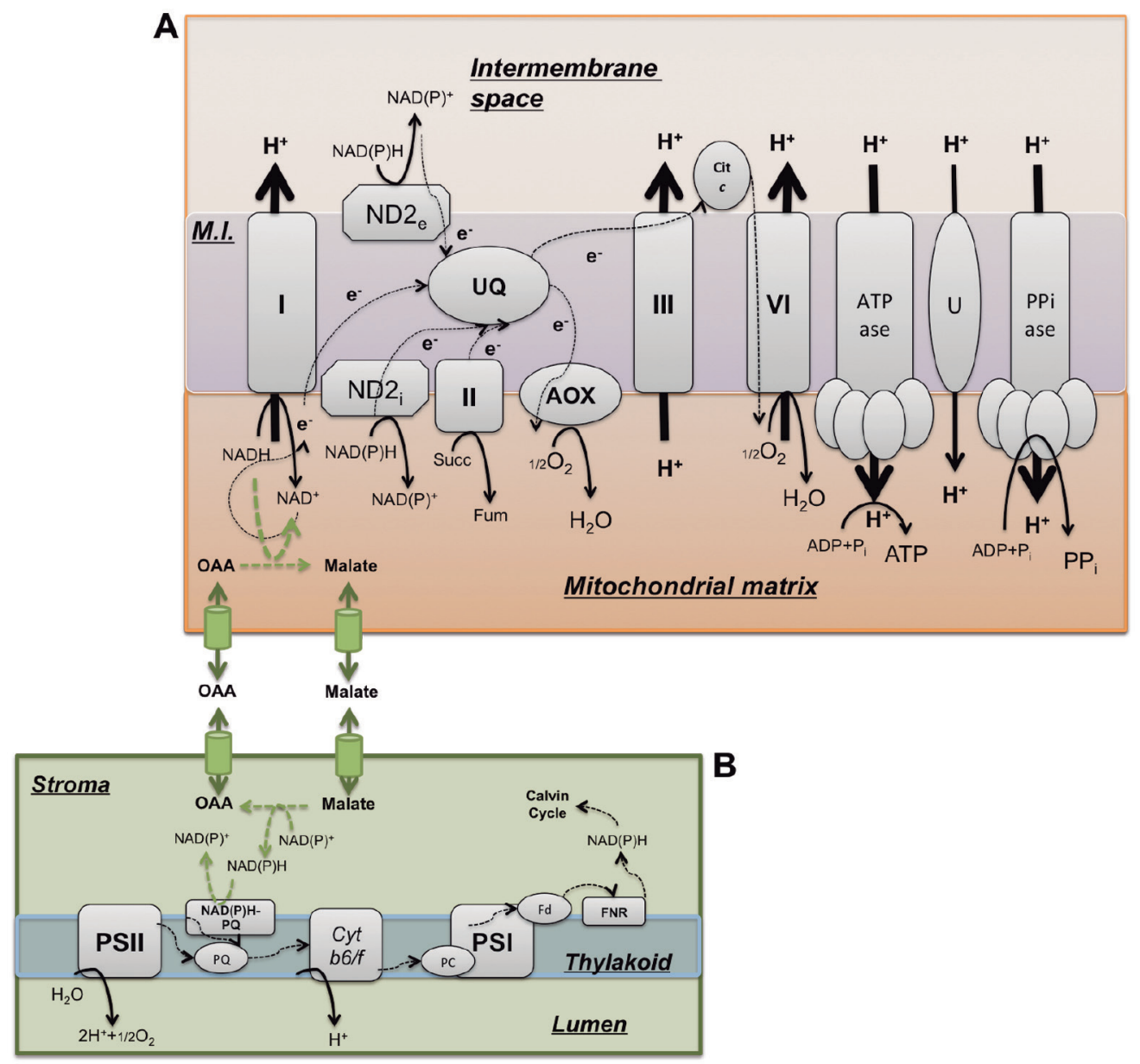

Source: Author based on Peltier and Cournac (2002) and Bauwe et al. (2010).

OXPHOS abbreviations: I: cytochrome I or NADH dehydrogenase, ND2 $2_{\mathrm{i}}$, ND2 ${ }_{\mathrm{e}}, \mathrm{NAD}(\mathrm{P}) \mathrm{H}$ dehydrogenase type II internal and external, respectively, II: cytochrome II or succinate dehydrogenase, UQ: ubiquinone, AOX: alternative oxidase; III: cytochrome c reductase or cytochrome $b c_{1}$, IV: cytochrome c oxidase or COX, ATPase: ATP synthase, U or UCP: uncoupling protein, PP $_{\mathrm{i}}$ asa: pyrophosphate synthase.

Chlororespiration abbreviations: OAA: oxaloacetate, PSII: photosystem II, PQ pool of plastoquinone, Ndh or NAD(P)H-PQ, NAD(P)H dehydrogenase complex or NAD(P)H-plastoquinone oxidoreductase, respectively, Cyt $b 6 / f$, cytochrome $b 6 / f$, PC: plastocyanin, PSI: photosystem I, Fd: ferredoxin, FNR: ferredoxin $\mathrm{NADP}^{+}$reductase.

Figure 3. Schematic representation of oxidative phosphorylation (OXPHOS) (A) and chlororespiration (B). 
the inner mitochondrial membrane is the force that drives ATP synthesis (Millar et al., 2011).

In plants, studies have focused on finding alternative pathways to the conventional OXPHOS pathway of the electron transport chain. For example, the participation of certain alternative pathways that involve proteins associated with complex I (Rasmusson et al., 2004) and AOX (Moore et al., 2002) has been proposed (Figure 3). However, non-phosphorylation pathways do not contribute to the generation of the inner-membrane proton gradient (Fernie et al., 2004). To overcome this deficiency in the proton gradient, plants have a strategy developed from uncoupling proteins (UCP) embedded in the inner mitochondrial membrane (Smith et al., 2004; ArnholdtSchmitt et al., 2006). Uncoupling proteins activity can enhance the transfer of protons into the mitochondria by controlling the rate of production of superoxides, and may even have some control over the TCA cycle, because increases in the UCP content can increase the rate of conversion of pyruvate to citrate (Smith et al., 2004).

In both plants and animals, once in the mitochondria, $\mathrm{NADH}$ and $\mathrm{FADH}_{2}$ are oxidized in a complex called NADH dehydrogenase or complex I (Figure 3A), which initiates the transfer of electrons through OXPHOS. In plants this complex has 46 subunits, of which only 32 are similar to complex I proteins present in animals (Millar et al., 2011). A study in Arabidopsis showed that plants without complex I could still survive in association with a complex I protein called $\mathrm{NAD}(\mathrm{P}) \mathrm{H}$ dehydrogenase (Fernie et al., 2004). According to their position on the inner mitochondrial membrane, there are two kinds of NADPH dehydrogenase, internal and external (ND2 and ND2 2 , respectively) (Rasmusson et al., 2004). The function of $\mathrm{ND} 2{ }_{\mathrm{e}}$ is related to the regulation of $\mathrm{NADH}$ and $\mathrm{NAD}(\mathrm{P}) \mathrm{H}$ reduced in the cytoplasm in response primarily to the cytoplasmic $\mathrm{Ca}$ concentration, while ND2i participates with substrates from the TCA cycle (Rasmusson et al., 2004).

Complex II (succinate dehydrogenase, SDH) is an enzyme shared between TCA cycle and OXPHOS (Figure 2 and 3). Succinate dehydrogenase has different functions depending on the tissue in which it is found. For example, some influence of SDH has been reported in leaves with phytochrome A, which controls the activity of SDH (Plaxton and Podestá, 2006). Complexes III and IV (cytochrome $\mathrm{c}$ reductase and cytochrome c oxidase (COX), respectively) correspond to the OXPHOS supercomplex, COX being a prime OXOPHOS terminal oxidase (Popov et al., 2010).

Despite COX, there is another terminal oxidase that is inserted in the inner mitochondrial membrane, called alternative oxidase (AOX) (Figure 3). Is was thought that AOX's function was to support the transfer of electrons when COX was at full capacity (van Dongen et al., 2011). Nevertheless, is known that both AOX and COX compete for electrons, because both are positioned at critical
OXOPHOS control points (Lambers, 1982). Studies have elucidated a crucial role of AOX in protecting against ROS produced during oxidative stress (van Dongen et al., 2011), and it can also influence mitochondrial adaptability to different kinds of stress (Moller, 2001; Rasmusson et al., 2009), even expressing mitochondrial genes in a wide variety of environments. AOX acts against ROS as follows: AOX allows electron transfer from ubiquinone (UQ) to $\mathrm{O}_{2}$, which high levels of reducing agents in the UQ pool can be dissipated through AOX, thus avoiding the formation of ROS (Polidoros et al., 2009).

\section{Chlororespiration}

In plants, it is possible for electron transport to $\mathrm{O}_{2}$ to occur in the presence of light through thylakoidal membranes of chloroplasts, via chlororespiration (Figure 3) (Polidoros et al., 2009), distinct from photorespiration (Bennoun, 1982; Peltier and Cournac, 2002) and the Mehler reaction. The function of this process is to ensure supplies of ATP and $\mathrm{NAD}(\mathrm{P}) \mathrm{H}$ generated by glycolysis for converting starch into triose phosphate (D-glyceraldehyde phosphate or dihydroxyacetone phosphate) (Bauwe et al., 2010; Maurino and Peterhansel, 2010). Both chloroplasts and mitochondria share similar mechanisms and control components, e.g. the electron transport is carried out in the membrane and shares the same membrane components (cytochrome, ion-S proteins, quinones and ATPase) (Bennoun, 1982). Although there are no exclusive carriers of $\mathrm{NAD}(\mathrm{P}) \mathrm{H}$ in the thylakoidal membrane, this may be performed indirectly through OAA-malate ports which allow the transport of malate (Figure 3), being oxidized by $\mathrm{NAD}^{+}$to produce $\mathrm{NADH}$ in the chloroplast stroma (Bennoun, 1982). The ability to transport reducing agents through the inner chloroplast membrane means that it is in communication with the rest of the cell. There have been studies on the importance of environmental changes in chlororespiration, with an increase in the activity and expression of a protein complex called NDH (homologous to complex I) (Peltier and Cournac, 2002). This complex catalyzes the transfer of electrons from $\mathrm{NAD}(\mathrm{P}) \mathrm{H}$ to plastoquinones (Rumeau et al., 2005). According to some authors, this complex is key in chlororespiration because it has an NADH dehydrogenase function in mitochondria. In turn, the Ndh complex regulates the proton gradient produced in the stroma, suggesting a role in the control of oxidative stress produced in the chloroplast stroma (Rumeau et al., 2005).

\section{Photorespiration}

Unlike chlororespiration, photorespiration (also called the $\mathrm{C}_{2}$ cycle) corresponds to an oxidation mechanism of $\mathrm{C}$ molecules (such as ribulose 1,5-diphosphate) and is performed in three different organelles: chloroplasts, mitochondria and peroxisomes (Peltier and Cournac, 2002). This process consists in replacing $\mathrm{CO}_{2}$ for $\mathrm{O}_{2}$ during $\mathrm{C}$ fixation in photosynthesis, allowing recycling 
and transforming the phosphoglycolate (2PG) generated into phosphoglycerate (Maurino and Peterhansel, 2010).

Photorespiration is one of the most important pathways of carbon metabolism in plants, exceeded in its importance at the terrestrial level only by photosynthesis. This is because of the high $\mathrm{O}_{2}$ concentration in the cells compared to $\mathrm{CO}_{2}$. Photorespiration can release about $20 \%$ of the $\mathrm{CO}_{2}$ that is absorbed during photosynthesis under normal temperatures. However, it was determined that the amount of $\mathrm{CO}_{2}$ released could be higher in hot and dry environments (Bauwe et al., 2010; Maurino and Peterhansel, 2010). The interaction between photorespiration and mitochondrial respiration is generated from an allosteric reaction in the TCA cycle using the products of the reaction catalyzed by glycine decarboxylase (GDC) and an interaction between NAD ${ }^{+}$ regenerated by the GDC and the electron transport chain (Figure 3B).

The importance of photosynthesis and photorespiration has been observed in tobacco (Nicotiana tabacum L.) mutants deficient in complex I expression for mitochondrial OXPHOS, because the proteins of complex I are important for maintaining the redox conditions in the cell that enhance photosynthetic efficiency (Peltier and Cournac, 2002; Plaxton and Podestá, 2006; van Dongen et al., 2011).

\section{Functions of plant respiration}

There is a great deal of information available about molecular and physiological aspects of plant respiration and its importance for plant growth and development. However, there is little information about the link between respiration and key processes in the survival of several plant species. Nine processes have been described to take priority from the energetic point of view: growth (Dutilleul et al., 2003), nitrate reduction, symbiotic N fixation, uptake of nitrate and other ions by roots (van Iersel and Seymour, 2000; Thongo M'Bou et al., 2010), protein turnover (Poorter et al., 1991), maintenance of protons gradient (De Visser et al., 1992; Bouma et al., 1994; Scheurwater et al., 2000), waste mechanisms and heat production by alternative pathways (Veen, 1980; Bouma and De Visser, 1993). Generally, these processes are associated with two components of respiration: growth and maintenance respiration (Johnson et al., 1998). Nevertheless, it is possible aggregate a third component when the correlation between relative growth rate (RGR) and net $\mathrm{N}$ uptake rate (NNUR) is not tight (Amthor, 2000; Thornley and Cannell, 2000).

Growth respiration is respiration that produces energy and $\mathrm{C}$ skeletons for the synthesis of new structures in growing plants (proteins, lipids, organic acids, and structural carbohydrates) (Veen, 1980). Maintenance respiration is respiration that produces energy for all processes related to cellular maintenance such as protein turnover, maintenance of ion gradients and membrane potentials in the cell (Penning de Vries et al., 1974; Penning de Vries, 1975). A mathematical expression of the relationship between these components of respiration is:

$$
R_{r}=R_{m}+c_{g} \cdot R G R+c_{u} \cdot N N U R
$$

where $R_{r}$ is root respiration rate $\left(\mu \mathrm{mol} \mathrm{O} \mathrm{O}_{2}\right.$ or $\left.\mathrm{CO}_{2} \mathrm{~g}^{-1} \mathrm{~d}^{-1}\right), R_{m}$ is respiration rate to produce ATP required for maintenance of biomass, $c_{g}$ is root respiration to produce ATP for cellular compound synthesis (mmols $\mathrm{O}_{2}$ or $\mathrm{CO}_{2} \mathrm{~g}^{-1}$ ), RGR is the relative growth rate of roots $\left(\mathrm{mg} \mathrm{g}^{-1} \mathrm{~d}^{-1}\right), c_{u}$ is the respiration rate required for maintenance $\left(\mu \mathrm{mol} \mathrm{g} \mathrm{g}^{-1} \mathrm{~d}^{-1}\right)$, and NNUR is the net $\mathrm{N}$ uptake rate (Veen, 1980).

The energy requirements for each process depend on the rates associated with them, which are affected by the species, organ (tissue) and environmental conditions to which the plants are subjected (Lambers, 2008). For example, Figure 4 shows that young plants under high $\mathrm{N}$ conditions allocated only $10 \%$ to the maintenance component of root respiration (Poorter et al., 1991). On the other hand, the growth component is an important

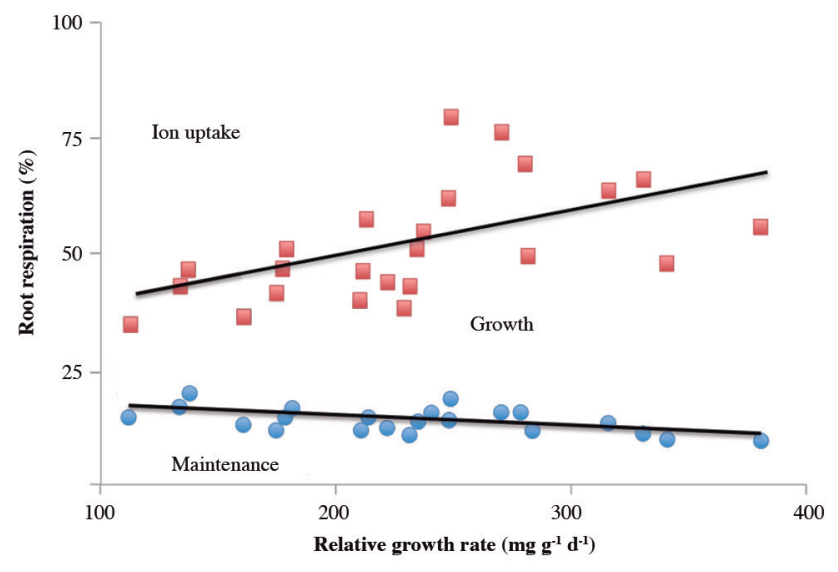

Source Poorter et al. (1991).

Figure 4. Respiratory costs associated with respiration components of maintenance, growth, and ion uptake. 
part of root respiration (20\%-45\%); however, the majority of the respiration is devoted to the ion uptake process (50\%-70\%) (Poorter et al., 1991). In a study in Carex, maintenance respiration was the most important component associated with respiration because fully grown plants were used, which meant lower RGR and NNUR (van der Werf et al., 1988).

Protein turnover corresponds to the major fraction of the maintenance component of respiration. It is particularly important when rapid changes occur in the environment or during periods of stress. Without this mechanism (protein turnover), the energy requirement would be increased by a high demand from the plant, so protein turnover could keeps the metabolism stable in a wide variety of environments and at all stages of development (van der Werf et al., 1988). It is estimated that between $2 \%$ and $5 \%$ of all proteins are replaced daily; however, there are reports indicating that protein turnover in leaves could be as much as $20 \%$ daily. Some of the processes associated with protein turnover are: biodegradation of proteins, activation and turnover of amino acids, peptide bond formation and posttranslational processes, among others (Bouma et al., 1994).

Some researchers working under different growth conditions, have correlated maintenance respiration rates and protein content of biomass (Poorter et al., 1991); thus, it can be inferred that protein turnover costs are the most important costs of maintenance respiration. In a comparative study on roots of fast-growing (Dactylis glomerata L.) and slow-growing (Festuca ovina L.), it was shown that the cost associated with protein turnover accounted for between $22 \%$ and $33 \%$ of daily ATP production, corresponding to $11 \%$ to $15 \%$ of the total production of ATP by roots (Hachiya et al., 2007). In leaves, protein turnover has been estimated at approximately $200 \mathrm{mmol} \mathrm{CO} \mathrm{kg}^{-1} \mathrm{~d}^{-1}$ (Scheurwater et al., 2000). Another portion of the costs associated with maintenance are dedicated to regulating the ionic gradient, also known as the cell's osmotic potential, where the costs of maintaining the ionic gradient are approximately 400 mmol CO${ }_{2} \mathrm{~kg}^{-1} \mathrm{~d}^{-1}$ (Amthor, 2000).

Otherwise, the growth component is usually expressed in $\mathrm{C}$ units ( $\mathrm{c}_{\mathrm{g}}$ from Equation [1]), corresponding to new biomass per unit of glucose (Penning de Vries, 1975). Most plant $\mathrm{c}_{\mathrm{g}}$ values are between 0.7 and 0.8 , equivalent to the cost of constructing the glucose requirement, with values of 1.2 to $1.4 \mathrm{~g}_{\text {glucose }} \mathrm{g}^{-1} \mathrm{DM}\left(0.2\right.$ to $0.4 \mathrm{~g} \mathrm{CO}_{2} \mathrm{~g}^{-1}$ DM) (Cannell and Thornley, 2000).

Currently, other studies focus on the contributions that terminal oxidases (COX and AOX) should have on the growth and maintenance components of plant respiration. In Arabidopsis plants, Cannell and Thornley (2000) estimated the construction cost of leaf tissues, which corresponded to 5.3 and $0.8 \mathrm{mmol} \mathrm{O}_{2} \mathrm{~g}^{-1} \mathrm{DM}$ for $\mathrm{COX}$ and $\mathrm{AOX}$, respectively, while maintenance respiration via COX and AOX was 14.3 and $9 \mathrm{nmol}$ $\mathrm{O}_{2} \mathrm{~g}^{-1} \mathrm{~s}^{-1}$. Similar values were found by Florez-Sarasa et al. (2007) in the same species. Respiration through COX consumed $90 \%$ and $60 \%$ of respired $\mathrm{C}$ for growth and maintenance, respectively, while AOX consumed 10\% and $40 \%$ of available $\mathrm{C}$ for growth and maintenance respiration, respectively (Bouma, 2005). These results show an interesting effect, because respiration through COX varies more in response to RGR than AOX (FlorezSarasa et al., 2007). When RGR is low (decreasing or not the respiration) AOX activity is increased, allowing it to maintain the redox state of the ubiquinone "pool" to inhibit ROS (Florez-Sarasa et al., 2007).

\section{Oxygen availability for plant respiration}

A major factor that affects plant respiration is $\mathrm{O}_{2}$ depletion, in the rhizosphere or directly in tissues. The $\mathrm{O}_{2}$ availability in tissues and cells depends on the plant's age and especially on the $\mathrm{O}_{2}$ supply from the environment, tissue $\mathrm{O}_{2}$ having a great influence on the central pathways of carbohydrate synthesis (Millar et al., 1998). In plants, the major external factors affecting $\mathrm{O}_{2}$ availability are flooding and waterlogging of soil (Liao and Lin, 2001). Under these conditions we can distinguish three broad categories of oxygen status induced by water: normoxia, hypoxia, and anoxia (Table 1). Excess water in soil decreases the $\mathrm{O}_{2}$ diffusion rate, because the diffusion of $\mathrm{O}_{2}$ is $10^{4}$ times slower in water than in air (Liao and Lin, 2001; Jackson and Colmer, 2005). The reason for this is the high level of interaction between $\mathrm{O}_{2}$ and $\mathrm{H}_{2} \mathrm{O}$ through hydrogen bonds (Mommer et al., 2004). In flooded soils not only is the diffusion of $\mathrm{O}_{2}$ reduced, but also the diffusion of several other gases such as $\mathrm{CO}_{2}$ and ethylene (Wegner, 2010). It is important to consider that low $\mathrm{O}_{2}$ availability in cells can even occur in some situations under normoxia, due mainly to a high resistance

Table 1. Description of three states of $\mathrm{O}_{2}$ deficiency due to excess water.

\begin{tabular}{|c|c|c|c|}
\hline & Normoxia & Hypoxia & Anoxia \\
\hline Metabolism ${ }^{1}$ & Aerobic & Enhanced anaerobic & Anaerobic \\
\hline $\mathrm{NAD}+$ regeneration $^{1}$ & $\begin{array}{l}\text { Oxidative phosphorylation (OXPHOS) } \\
\text { pathway }\end{array}$ & $\begin{array}{l}\text { Alcoholic and lactic } \\
\text { fermentation pathways }\end{array}$ & $\begin{array}{l}\text { Alcoholic and lactic fermentation } \\
\text { pathways }\end{array}$ \\
\hline ATP production ${ }^{1}$ & $\approx 30-36 \mathrm{~mol}$ ATP $\mathrm{mol}^{-1}$ glucose consumed & Dependent on species & $\approx 4 \mathrm{~mol} \mathrm{ATP} \mathrm{mol}^{-1}$ of glucose consumed \\
\hline ATP and/or ADP cellular content ${ }^{1}$ & Normal & Low ATP & Low ATP and high ADP \\
\hline Oxygen content ${ }^{2}$ & $8.0-8.5 \mathrm{mg} \mathrm{O}_{2} \mathrm{~L}^{-1}$ & $1.5-6.0 \mathrm{mg} \mathrm{O}_{2} \mathrm{~L}^{-1}$ & $0 \mathrm{mg} \mathrm{O}_{2} \mathrm{~L}^{-1}$ \\
\hline
\end{tabular}

$8.5 \mathrm{mg} \mathrm{O}_{2} \mathrm{~L}^{-1}=21 \% \mathrm{O}_{2}=270 \mu \mathrm{M} \mathrm{O}_{2}=100 \% \mathrm{O}_{2}$ saturation. The oxygen content defined for each condition is not the same for all species.

${ }^{1}$ Moore et al. (2002); Sweetlove et al. (2010).

${ }^{2}$ Moore et al. (2002); Arnholdt-Schmitt et al. (2006). 
to $\mathrm{O}_{2}$ diffusion between different plant tissues (Gibbs and Greenway, 2003) such as roots and stems (van Dongen et al., 2011).

Sometimes, to reduce the anaerobic state in shoots, roots regulate frequency of absorption (Armstrong et al., 1994; Zabalza et al., 2009) and oxygen consumption (Mancuso and Marras, 2006). Morphological adaptations also play a key supporting role in promoting the $\mathrm{O}_{2}$ flux from the roots through the rest of the plant, e.g. aerenchyma formation due to induction by ethylene (Greenway and Gibbs, 2003). One of the main effects of anaerobiosis on metabolism is a decreased adenylate energy charge (AEC), which also reduces the ATP:ADP ratio (Drew et al., 2000).

Under hypoxic conditions the TCA cycle pathway gives more flexibility to the overall metabolism (Table 1). For instance, in Lotus japonicus, it was shown that alanine aminotransferase (AlaAT) generates a link between glycolysis and the TCA cycle through the conversion of 2-oxoglutarate to succinate. This generates NADH that is used in the transformation of OAA into malate; together with succinate CoA ligase, both contribute to the generation of ATP under conditions of oxygen deficit (Geigenberger, 2003; Bailey-Serres and Voesenek, 2008).

Moreover, glycolysis is affected when $\mathrm{O}_{2}$ concentration falls below 1.5-2.0 mg $\mathrm{O}_{2} \mathrm{~L}^{-1}$ in the bulk solution (hypoxia). This decreases glycolysis and increases the activities of enzymes involved in fermentation ( $\mathrm{Li}$ et al., 2010). In maize subjected to hypoxia, PDC activity increases 5-to-9-fold compared to that under normal conditions (Gupta et al., 2009). It is known that there are two major control points for electron transfer under oxygen deficit, corresponding to AOX and COX. Some studies suggest that the response to oxygen deficiency in roots is driven by the terminal oxidation of respiration (Kennedy et al., 1992). Under some conditions, when the availability of $\mathrm{O}_{2}$ in roots is decreased, adaptation to stress may occur through two strategies; the first is a decrease in ATP consumption which leads to a metabolic crisis at the cellular level (Igamberdiev et al., 2010), and the second is an increase in the glycolytic flux (Mancuso and Marras, 2006). The latter is called the "Pasteur effect" (Gibbs et al., 2000), consisting of a progressive acceleration in carbohydrate metabolism that allows the plants to maintain their energy level, especially during the early phase of acclimation to oxygen deficiency (Turner, 1951; Greenway and Gibbs, 2003; Camacho-Pereira et al., 2009; Wegner, 2010).

Although many authors emphasize the importance of the "Pasteur effect" in acclimatization processes to compensate for the energy inefficiency caused by OXPHOS inhibition (Gibbs and Greenway, 2003; Huang et al., 2008), this can only generate ATP at about $37.5 \%$ of the rate produced in tissues under optimal oxygen conditions (Geigenberger, 2003).

The $\mathrm{O}_{2}$ is a molecule that participates as a final electron acceptor in the transport chain complexes (Gibbs and Greenway, 2003); therefore, when oxygen availability decreases dramatically in the rhizosphere (anoxia, Table 1), OXPHOS is inactivated (Moller, 2001) and terminal oxidase (COX) is inhibited (Liao and Lin, 2001; Greenway and Gibbs, 2003; Mancuso and Marras, 2006; Mailloux et al., 2007). Under these conditions, plants have developed alternative pathways to aerobic respiration in order to maintain glycolysis through the regeneration of $\mathrm{NAD}^{+}$(Gupta et al., 2009) and thus obtain the energy needed to maintain key processes of metabolism such as membrane integrity and thus ion selectivity (Tadege et al., 1999), protein synthesis and turnover and regulation of cytosolic $\mathrm{pH}$, among others (Blokhina et al., 2003). These alternative pathways are known as fermentations.

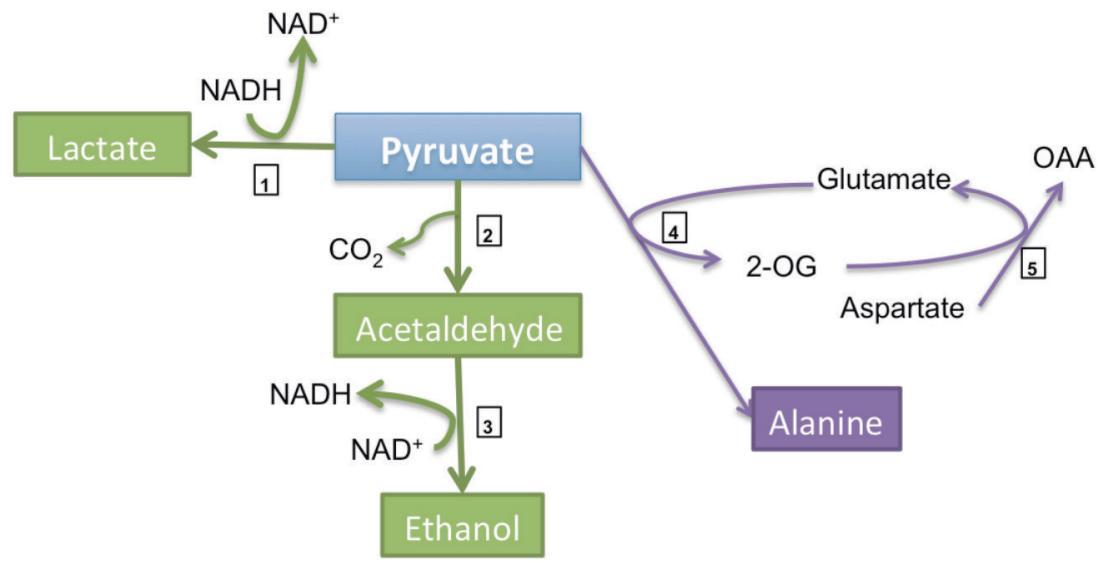

Source: Author based on Gupta et al. (2009).

OAA: Oxaloacetate.

Figure 5. Representation of anaerobic respiration. Green boxes and arrows show the lactic acid and alcoholic fermentation. Purple boxes and arrows show the cycle that involves alanine. 
Three fermentative pathways are known (Greenway and Gibbs, 2003) that are active under conditions of oxygen deficiency (Figure 5): alcoholic fermentation, lactic fermentation (Sousa and Sodek, 2002) and the alanine pathway; the last one is specific to plants and its final product is alanine from glutamate and the pyruvate reaction (Tadege et al., 1999). There are also other final products of fermentation such as succinate, malate, and $\gamma$-aminobutyric acid (Dennis et al., 2000).

From the energy point of view, fermentative pathways can produce between $5 \%$ and $10 \%$ of the ATP per mole of glucose oxidized in aerobic respiration (Drew, 1997; Sousa and Sodek, 2002). In the roots of grapevines, for example, under normal conditions about $22.5 \mathrm{nmol}$ ATP $\mathrm{g}^{-1}$ fresh weight are obtained, but in anoxia only $2 \mathrm{nmol}$ ATP g ${ }^{-1}$ fresh weight are produced (Geigenberger, 2003).

The activation of a fermentation pathway is usually initiated when an anaerobic event occurs (Tadege et al., 1999; Bailey-Serres and Voesenek, 2008); later, the pyruvate is reduced to lactic acid by lactate dehydrogenase (LDH) in the cell's cytoplasm (Tadege et al., 1999). LDH acts at a pH near 7.4 (Kato-Noguchi and Morokuma, 2007) and is responsible for maintaining the redox balance without the loss of $\mathrm{C}$ associated with alcoholic fermentation. However, the accumulation of this enzyme leads to a decrease in cytosolic $\mathrm{pH}$ to levels between 6.4 and 6.8 (Tadege et al., 1999). Acidification of the cytoplasm inactivates LDH and activates pyruvate decarboxylase (PDC) (Roberts et al., 1984), which decarboxylates pyruvate and forms acetaldehyde, which in turn is finally reduced to ethanol by alcohol dehydrogenase (ADH) (Felle, 2005). In Vitis riparia Michx. and V. rupestri Scheele plants subjected to anoxia during $24 \mathrm{~h}$, both species showed high levels of ethanol as the principal component of fermentation, yielding 225 and $175 \mu \mathrm{mol} \mathrm{g}^{-1}$ fresh weight (V. riparia and $V$. rupestri, respectively) at $20 \mathrm{~h}$ of treatment. Under normal conditions the level was $40 \mu \mathrm{mol} \mathrm{g}^{-1}$ fresh weight (Tadege et al., 1999; Kato-Noguchi and Morokuma, 2007). The importance of alcoholic fermentation in tolerance to oxygen deficiency has also been shown in rice, where the response of different cultivars to $48 \mathrm{~h}$ of anoxia has been demonstrated. This study showed that at the end of the treatment LDH activity was insignificant. In contrast, $\mathrm{PCD}$ and $\mathrm{ADH}$ activities were, on average, were induced 9-fold compared with their status in the same coleoptiles under normal conditions (Mancuso and Marras, 2006).

Evaluation in Arabidopsis mutants has indicated that overexpression of PCD and ADH promotes stress tolerance during oxygen deficiency, because the carbon flux is controlled through alcoholic fermentation and through the lactate and alanine pathways (KatoNoguchi and Morokuma, 2007). Nevertheless, additional information about the special features associated with fermentative pathways, and specifically alcoholic fermentation, where the absence of oxygen would not be responsible for inducing enzymes such as PCD and ADH, is highly desirable (Kennedy et al., 1992; Rahman et al., 2001; Ismond et al., 2003; Kursteiner et al., 2003).

\section{CONCLUSIONS}

Plant respiration is a highly dynamic process, because the pathways involved present a high capacity to adapt to different environmental conditions. Glycolysis is one of these pathways; controlling several reactions in which exist two key enzymes participating as control points: hexokinase and pyruvate kinase. Both enzymes can control glycolysis not only in mitochondria but also at a posttranslational level.

The tricarboxylic acid (TCA) cycle has a strong influence on respiration metabolism through enzymatic control. The TCA cycle is not only involved in regulating the respiration rate, but also participates in the synthesis of intermediates of the same cycle such as isocitrate, malate, and succinate. In turn, the TCA cycle regulates some key processes in photosynthetic metabolism such as $\mathrm{CO}_{2}$ assimilation. The existence of alternative pathways such as GABA and the glyoxylate cycle gives the TCA cycle further plasticity in adapting to environmental changes.

There is little information with respect to the link between energy for respiration and processes important for a plant metabolism. Components of respiration associated with growth and ion uptake are highly dependent on factors such as the species, plant organ and environmental conditions affecting the relative growth rate and net $\mathrm{N}$ uptake rate coefficients. The maintenance component also responds favorably to rapid changes in the environment, due to its high capacity to modify protein turnover in the cells.

A plant's capacity to tolerate anaerobic conditions not only relates to biochemical properties of the roots, but also the plant's capacity to transport $\mathrm{O}_{2}$ transport from oxygenated organs to anoxic organs. Both glycolysis and fermentation are principal mechanisms of energy maintenance in the cells and their function is important in a plant's tolerance to $\mathrm{O}_{2}$ deficiency.

Plant respiration is considered a principal mechanism of ecosystem maintain on the planet. Therefore, it is important that new research should focus on predicting the impact that climate change will have on respiratory metabolism, especially at the functional and genomic levels.

\section{ACKNOWLEDGEMENTS}

We thank the Centro de Estudios Avanzados en Fruticultura (CEAF) and the CONICYT Regional project R08I1001 for financing this review. The authors wish to thank to professor Tim Colmer for critical review of the manuscript. 


\section{LITERATURE CITED}

Amthor, J.S. 2000. The McCree-de Wit-Penning de Vries-Thornley Respiration Paradigms: 30 Years Later. Annals of Botany 86:1-20.

Armstrong, W., M.E. Strange, S. Cringle, and P.M. Beckett. 1994. Microelectrode and modelling study of oxygen distribution in roots. Annals of Botany 74:287-299.

Arnholdt-Schmitt, B., J.H. Costa, and D.F. de Melo. 2006. AOX - a functional marker for efficient cell reprogramming under stress? Trends in Plant Science 11:281-287.

Atkin, O.K., J.R. Evans, M.C. Ball, H. Lambers, and T.L. Pons. 2000. Leaf respiration of snow gum in the light and dark. Interactions between temperature and irradiance. Plant Physiology 122:915-924.

Atkin, O.K., J.R. Evans, and K. Siebke. 1998. Relationship between the inhibition of leaf respiration by light and enhancement of leaf dark respiration following light treatment. Australian Journal of Plant Physiology 25:437-443.

Atkin, O.,A. Millar,P.Gardeström, and D. Day. 2004. Photosynthesis, carbohydrate metabolism and respiration in leaves of higher plants. p. 153-175. In Leegood, R., T. Sharkey, and S. Caemmerer (eds.) Photosynthesis. Springer, Dordrecht, The Netherlands.

Aurisano, N., A. Bertani, and R. Reggiani. 1995. Involvement of calcium and calmodulin in protein and amino acid metabolism in rice roots under anoxia. Plant and Cell Physiology 36:1525-1529.

Azama, K., S. Abe, H. Sugimoto, and E. Davies. 2003. Lysinecontaining proteins in maize endosperm: A major contribution from cytoskeleton-associated carbohydrate-metabolizing enzymes. Planta 217:628-638.

Bailey-Serres, J., and L. Voesenek. 2008. Flooding stress: Acclimations and genetic diversity. Annual Review of Plant Biology 59:313-339.

Bauwe, H., M. Hagemann, and A.R. Fernie. 2010. Photorespiration: players, partners and origin. Trends in Plant Science 15:330-336.

Bennoun, P. 1982. Evidence for a respiratory chain in the chloroplast. Proceedings of the National Academy of Sciences of USA 79:4352-4356.

Bernstein, N., A. Eshel, and T. Beeckman. 2013. Effects of salinity on root growth. CRC Press, Boca Raton, Florida, USA.

Blokhina, O., E. Virolainen, and K.V. Fagerstedt. 2003. Antioxidants, oxidative damage and oxygen deprivation stress: A review. Annals of Botany 91:179-194.

Bouché, N., and H. Fromm. 2004. GABA in plants: just a metabolite? Trends in Plant Science 9:110-115.

Bouma, T. 2005. Understanding plant respiration: Separating respiratory components versus a process-based approach. p. 177194. In Lambers, H., and M. Ribas-Carbo (eds.) Plant respiration. Springer, Dordrecht, The Netherlands.

Bouma, T.J., and R. De Visser. 1993. Energy requirements for maintenance of ion concentrations in roots. Physiologia Plantarum 89:133-142.

Bouma, T.J., R. De Visser, J. Janssen, M. De Kock, P. Van Leeuwen, and H. Lambers. 1994. Respiratory energy requirements and rate of protein turnover in vivo determined by the use of an inhibitor of protein synthesis and a probe to assess its effect. Physiologia Plantarum 92:585-594.

Camacho-Pereira, J., L.E. Meyer, L.B. Machado, M.F. Oliveira, and A. Galina. 2009. Reactive oxygen species production by potato tuber mitochondria is modulated by mitochondrially bound hexokinase activity. Plant Physiology 149:1099-1110.

Cannell, M.G.R., and J.H.M. Thornley. 2000. Modelling the components of plant respiration: Some guiding principles. Annals of Botany 85:45-54.

de Sousa, C.A.F., and L. Sodek. 2003. Alanine metabolism and alanine aminotransferase activity in soybean (Glycine max) during hypoxia of the root system and subsequent return to normoxia. Environmental and Experimental Botany 50:1-8.
De Visser, R., C.J.T. Spitters, and T.J. Bouma. 1992. Energy costs of protein turnover: Theoretical calculation and experimental estimation from regression of respiration on protein concentration of fullgrown leaves. p. 493-508. In Lambers, H., L.H.W. van der Plas (eds.) Molecular, biochemical and physiological aspects of plant respiration. SPB Academic Publishing, Amsterdam, The Netherlands.

Dennis, E.S., R. Dolferus, M. Ellis, M. Rahman, Y. Wu, F.U. Hoeren, et al. 2000. Molecular strategies for improving waterlogging tolerance in plants. Journal of Experimental Botany 51:89-97.

Drew, M.C. 1997. Oxygen deficiency and root metabolism: Injury and acclimation under hypoxia and anoxia. Annual Review of Plant Physiology and Plant Molecular Biology 48:223-250.

Drew, M.C., C.J. He, and P.W. Morgan. 2000. Programmed cell death and aerenchyma formation in roots. Trends in Plant Science 5:123-127.

Dutilleul, C., S. Driscoll, G. Cornic, R. De Paepe, C.H. Foyer, and G. Noctor. 2003. Functional mitochondrial complex I Is required by tobacco leaves for optimal photosynthetic performance in photorespiratory conditions and during transients. Plant Physiology 131:264-275.

Eastmond, P.J., V. Germain, P.R. Lange, J.H. Bryce, S.M. Smith, and I.A. Graham. 2000. Postgerminative growth and lipid catabolism in oilseeds lacking the glyoxylate cycle. Proceedings of the National Academy of Sciences of United States of America 97:5669-5674.

Eastmond, P.J., and I.A. Graham. 2001. Re-examining the role of the glyoxylate cycle in oilseeds. Trends in Plant Science 6:72-78.

Felle, H.H. 2005. pH regulation in anoxic plants. Annals of Botany 96:519-532.

Fernie, A.R., F. Carrari, and L.J. Sweetlove. 2004. Respiratory metabolism: Glycolysis, the TCA cycle and mitochondrial electron transport. Current Opinion in Plant Biology 7:254-261.

Finkelstein, R., and S. Gibson. 2002. ABA and sugar interactions regulating development: Cross-talk or voices in a crowd? Current Opinion in Plant Biology 5:26-32.

Florez-Sarasa, I.D., T.J. Bouma, H. Medrano, J. Azcon-Bieto, and M. Ribas-Carbo. 2007. Contribution of the cytochrome and alternative pathways to growth respiration and maintenance respiration in Arabidopsis thaliana. Physiologia Plantarum 129:143-151.

Geigenberger, P. 2003. Response of plant metabolism to too little oxygen. Current Opinion in Plant Biology 6:247-256.

Gibbs, J., and H. Greenway. 2003. Review: Mechanisms of anoxia tolerance in plants. I. Growth, survival and anaerobic catabolism. Functional Plant Biology 30:1-47.

Gibbs, J., S. Morrell, A. Valdez, T.L. Setter, and H. Greenway. 2000 Regulation of alcoholic fermentation in coleoptiles of two rice cultivars differing in tolerance to anoxia. Journal of Experimental Botany 51:785-796.

Giegé, P., J.L. Heazlewood, U. Roessner-Tunali, A.H. Millar, A.R. Fernie, C.J. Leaver, et al. 2003. Enzymes of glycolysis are functionally associated with the mitochondrion in Arabidopsis cells. The Plant Cell 15:2140-2151.

Greenway, H., and J. Gibbs. 2003. Review: Mechanisms of anoxia tolerance in plants. II. Energy requirements for maintenance and energy distribution to essential processes. Functional Plant Biology 30:999-1036.

Gupta, K.J., A. Zabalza, and J.T. Van Dongen. 2009. Regulation of respiration when the oxygen availability changes. Physiologia Plantarum 137:383-391.

Hachiya, T., I. Terashima, and K. Noguchi. 2007. Increase in respiratory cost at high growth temperature is attributed to high protein turnover cost in Petunia $\times$ hybrida petals. Plant, Cell and Environment 30:1269-1283.

Hajirezaei, M.-R., S. Biemelt, M. Peisker, A. Lytovchenko, A.R Fernie, and U. Sonnewald. 2006. The influence of cytosolic phosphorylating glyceraldehyde 3-phosphate dehydrogenase (GAPC) on potato tuber metabolism. Journal of Experimental Botany 57:2363-2377. 
Huang, S., T.D. Colmer, and A.H. Millar. 2008. Does anoxia tolerance involve altering the energy currency towards PPi? Trends in Plant Science 13:221-227.

Igamberdiev, A.U., N.V. Bykova, J.K. Shah, and R.D. Hill. 2010. Anoxic nitric oxide cycling in plants: participating reactions and possible mechanisms. Physiologia Plantarum 138:393-404.

Ismond, K.P., R. Dolferus, M. de Pauw, E.S. Dennis, and A.G. Good. 2003. Enhanced low oxygen survival in Arabidopsis through increased metabolic flux in the fermentative pathway. Plant Physiology 132:1292-1302.

Jackson, M.B., and T.D. Colmer. 2005. Response and adaptation by plants to flooding stress. Annals of Botany 96:501-505.

Jenner, H.L., B.M. Winning, A.H. Millar, K.L. Tomlinson, C.J. Leaver, and S.A. Hill. 2001. NAD Malic enzyme and the control of carbohydrate metabolism in potato tubers. Plant Physiology 126:1139-1149.

Jiménez, S., J. Dridi, D. Gutiérrez, D. Moret, J.J. Irigoyen, M.A. Moreno, et al. 2013. Physiological, biochemical and molecular responses in four Prunus rootstocks submitted to drought stress. Tree Physiology 33:1061-1075.

Johnson, J.D., J.G. Mehus, K. Tews, B.I. Milavetz, and D.O. Lambeth. 1998. Genetic evidence for the expression of ATP- and GTP-specific succinyl-CoA synthetases in multicellular eukaryotes. The Journal of Biological Chemistry 273:27580-27586.

Kato-Noguchi, H., and M. Morokuma. 2007. Ethanolic fermentation and anoxia tolerance in four rice cultivars. Journal of Plant Physiology 164:168-173.

Kennedy, R.A., M.E. Rumpho, and T.C. Fox. 1992. Anaerobic metabolism in plants. Plant Physiology 100:1-6.

Kim, M., J.-H. Lim, C.S. Ahn, K. Park, G.T. Kim, W.T. Kim, et al. 2006. Mitochondria-associated hexokinases play a role in the control of programmed cell death in Nicotiana benthamiana. The Plant Cell 18:2341-2355.

Kinnersley, A.M., and F.J. Turano. 2000. Gamma aminobutyric acid (GABA) and plant responses to stress. Critical Reviews in Plant Sciences 19:479-509.

Kornberg, H.L., and N.B. Madsen. 1958. The metabolism of C2 compounds in micro-organisms. 3. Synthesis of malate from acetate via the glyoxylate cycle. Biochemical Journal 68:549-557.

Kursteiner, O., I. Dupuis, and C. Kuhlemeier. 2003. The pyruvate decarboxylase 1 gene of Arabidopsis is required during anoxia but not other environmental stresses. Plant Physiology 132:968-978.

Lambers, H. 1982. Cyanide-resistant respiration: A nonphosphorylating electron transport pathway acting as an energy overflow. Physiologia Plantarum 55:478-485.

Lambers, H. 2008. Respiration associated with growth, maintenance, and ion uptake. p. 134-140. In Lambers, H., F. Chapin, and T. L. Pons (eds.) Plant Physiological Ecology. Springer-Verlag, New York, USA.

Li, C., T. Bai, F. Ma, and M. Han. 2010. Hypoxia tolerance and adaptation of anaerobic respiration to hypoxia stress in two Malus species. Scientia Horticulturae 124:274-279.

Liao, C.T., and C.H. Lin. 2001. Physiological adaptation of crop plants to flooding stress. Proceedings of the National Science Council, Republic of China. Part B, Life Sciences 25:148-157.

Lu, M., L.S. Holliday, L. Zhang, W.A. Dunn, and S.L. Gluck. 2001. Interaction between aldolase and vacuolar $\mathrm{H}^{+}$-ATPase. The Journal of Biological Chemistry 276:30407-30413.

Mailloux, R.J., R. Bériault, J. Lemire, R. Singh, D.R. Chénier, R.D. Hamel, et al. 2007. The tricarboxylic acid cycle, an ancient metabolic network with a novel twist. PLoS ONE 2:e690.

Mancuso, S., and A.M. Marras. 2006. Adaptive response of Vitis root to anoxia. Plant and Cell Physiology 47:401-409.

Maurino, V.G., and C. Peterhansel. 2010. Photorespiration: Current status and approaches for metabolic engineering. Current Opinion in Plant Biology 13:248-255.

Millar, A.H., O.K. Atkin, R. Ian Menz, B. Henry, G. Farquhar, and D.A. Day. 1998. Analysis of respiratory chain regulation in roots of soybean seedlings. Plant Physiology 117:1083-1093
Millar, A.H., J. Whelan, K.L. Soole, and D.A. Day. 2011. Organization and regulation of mitochondrial respiration in plants. Annual Review of Plant Biology 62:79-104.

Moller, I.M. 2001. Plant mitochondria and oxidative stress: Electron transport, NADPH turnover, and metabolism of reactive oxygen species. Annual Review of Plant Physiology and Plant Molecular Biology 52:561-591.

Mommer, L., O. Pedersen, and E.J.W. Visser. 2004. Acclimation of a terrestrial plant to submergence facilitates gas exchange under water. Plant, Cell and Environment 27:1281-1287.

Moore, A.L., M.S. Albury, P.G. Crichton, and C. Affourtit. 2002. Function of the alternative oxidase: Is it still a scavenger? Trends in Plant Science 7:478-481.

Moore, B., L. Zhou, F. Rolland, Q. Hall, W.-H. Cheng, Y.-X. Liu, et al. 2003. Role of the Arabidopsis glucose sensor $\mathrm{HXK}_{1}$ in nutrient, light, and hormonal signaling. Science 300:332-336.

Moyen, C., and G. Roblin. 2013. Occurrence of interactions between individual $\mathrm{Sr}^{2+}$ - and $\mathrm{Ca}^{2+}$-effects on maize root and shoot growth and $\mathrm{Sr}^{2+}, \mathrm{Ca}^{2+}$ and $\mathrm{Mg}^{2+}$ contents, and membrane potential: Consequences on predicting $\mathrm{Sr}^{2+}$-impact. Journal of Hazardous Materials 260:770-779.

Muñoz-Bertomeu, J., B. Cascales-Minana, M. Alaiz, J. Segura, and R. Ros. 2010. A critical role of plastidial glycolytic glyceraldehyde3-phosphate dehydrogenase in the control of plant metabolism and development. Plant Signaling \& Behavior 5:67-69.

Oliver, S.N., J.E. Lunn, E. Urbanczyk-Wochniak, A. Lytovchenko, J.T. van Dongen, B. Faix, et al. 2008. Decreased expression of cytosolic pyruvate kinase in potato tubers leads to a decline in pyruvate resulting in an in vivo repression of the alternative oxidase. Plant Physiology 148:1640-1654.

Peltier, G., and L. Cournac. 2002. Chlororespiration. Annual Review of Plant Biology 53:523-550.

Penning de Vries, F.W.T. 1975. The cost of maintenance processes in plant cells. Annals of Botany 39:77-92.

Penning de Vries, F.W.T., A.H. Brunsting, and H.H. van Laar. 1974. Products, requirements and efficiency of biosynthesis: a quantitative approach. Journal of Theoretical Biology 45:339-377.

Plaxton, W.C. 1996. The organization and regulation of plant glycolysis. Annual Review of Plant Physiology and Plant Molecular Biology 47:185-214.

Plaxton, W., and F.E. Podestá. 2006. The functional organization and control of plant respiration. Critical Reviews in Plant Sciences 25:159-198.

Polidoros, A.N., P.V. Mylona, and B. Arnholdt-Schmitt. 2009. Aox gene structure, transcript variation and expression in plants. Physiologia Plantarum 137:342-353.

Poorter, H., A. Van der Werf, O.K. Atkin, and H. Lambers. 1991. Respiratory energy requirements of roots vary with the potential growth rate of a plant species. Physiologia Plantarum 83:469-475.

Popov, V.N., A.T. Eprintsev, D.N. Fedorin, and A.U. Igamberdiev. 2010. Succinate dehydrogenase in Arabidopsis thaliana is regulated by light via phytochrome A. FEBS Letters 584:199-202.

Rachmilevitch, S., H. Lambers, and B. Huang. 2006. Root respiratory characteristics associated with plant adaptation to high soil temperature for geothermal and turf-type Agrostis species. Journal of Experimental Botany 57:623-631.

Rahman, M., A. Grover, W.J. Peacock, E.S. Dennis, and M.H. Ellis. 2001. Effects of manipulation of pyruvate decarboxylase and alcohol dehydrogenase levels on the submergence tolerance of rice. Functional Plant Biology 28:1231-1241.

Rasmusson, A.G., A.R. Fernie, and J.T. van Dongen. 2009. Alternative oxidase: a defence against metabolic fluctuations? Physiologia Plantarum 137:371-382.

Rasmusson, A.G., K.L. Soole, and T.E. Elthon. 2004. Alternative $\mathrm{NAD}(\mathrm{P}) \mathrm{H}$ dehydrogenases of plant mitochondria. Annual Review of Plant Biology 55:23-39.

Roberts, J.K., J. Callis, O. Jardetzky, V. Walbot, and M. Freeling. 1984. Cytoplasmic acidosis as a determinant of flooding intolerance in plants. Proceedings of the National Academy of Sciences of United States of America 81:6029-6033. 
Rolland, F., B. Moore, and J. Sheen. 2002. Sugar sensing and signaling in plants. The Plant Cell 14:S185-S205.

Rumeau, D., N. Bécuwe-Linka, A. Beyly, M. Louwagie, J. Garin, and G. Peltier. 2005. New subunits NDH-M, -N, and -O, encoded by nuclear genes, are essential for plastid Ndh complex functioning in higher plants. The Plant Cell 17:219-232.

Ryan, P., E. Delhaize, and D. Jones. 2001. Function and mechanism of organic anion exudation from plant roots. Annual Review of Plant Physiology and Plant Molecular Biology 52:527-560.

Scheurwater, I., M. Dünnebacke, R. Eising, and H. Lambers. 2000 . Respiratory costs and rate of protein turnover in the roots of a fast-growing (Dactylis glomerata L.) and a slow-growing (Festuca ovina L.) grass species. Journal of Experimental Botany 51:1089-1097.

Sheen, J. 2014. Master regulators in plant glucose signaling networks. Journal of Plant Biology 57:67-79.

Smith, A.M.O., R.G. Ratcliffe, and L.J. Sweetlove. 2004. Activation and function of mitochondrial uncoupling protein in plants. The Journal of Biological Chemistry 279:51944-51952.

Sousa, C.A.F. de, and L. Sodek. 2002. The metabolic response of plants to oxygen deficiency. Brazilian Journal of Plant Physiology 14:83-94.

Studart-Guimaraes, C., A. Fait, A. Nunes-Nesi, F. Carrari, B. Usadel, and A.R. Fernie. 2007. Reduced expression of succinylcoenzyme A ligase can be compensated for by up-regulation of the $\gamma$-aminobutyrate shunt in illuminated tomato leaves. Plant Physiology 145:626-639.

Sweetlove, L.J., K.F.M. Beard, A. Nunes-Nesi, A.R. Fernie, and R.G. Ratcliffe. 2010. Not just a circle: flux modes in the plant TCA cycle. Trends in Plant Science 15:462-470.

Tadege, M., I.I. Dupuis, and C. Kuhlemeier. 1999. Ethanolic fermentation: New functions for an old pathway. Trends in Plant Science 4:320-325.

Taiz, L., and E. Zeiger. 1991. Plant physiology. 591 p. Benjamin Cummings Publishing, San Francisco, California, USA

Teusink, B., J. Passarge, C.A. Reijenga, E. Esgalhado, C.C. van der Weijden, M. Schepper, et al. 2000. Can yeast glycolysis be understood in terms of in vitro kinetics of the constituent enzymes? Testing biochemistry. European Journal of Biochemistry 267:5313-5329.
Thongo M'Bou, A., L. Saint-André, A. de Grandcourt, Y. Nouvellon, C. Jourdan, F. Mialoundama, et al. 2010. Growth and maintenance respiration of roots of clonal Eucalyptus cuttings: scaling to standlevel. Plant and Soil 332:41-53.

Thornley, J.H.M., and M.G.R. Cannell. 2000. Modelling the components of plant respiration: Representation and realism. Annals of Botany 85:55-67.

Turner, J.S. 1951. Respiration the Pasteur effect in plants. Annual Review of Plant Physiology and Plant Molecular Biology 2:145-168.

van der Werf, A., A. Kooijman, R. Welschen, and H. Lambers. 1988 Respiratory energy costs for the maintenance of biomass, for growth and for ion uptake in roots of Carex diandra and Carex acudformis. Physiologia Plantarum 72:483-491.

van Dongen, J.T., K.J. Gupta, S.J. Ramírez-Aguilar, W.L. Araújo, A. Nunes-Nesi, and A.R. Fernie. 2011. Regulation of respiration in plants: A role for alternative metabolic pathways. Journal of Plant Physiology 168:1434-1443.

van Iersel, M.W., and L. Seymour. 2000. Growth respiration, maintenance respiration, and carbon fixation of Vinca: A time series analysis. Journal of the American Society of Horticultural Science 125:702-706.

Veen, B.W. 1980. Energy cost of ion transport. p. 187-195. In D.W. Rains, R.C. Valentine, and A. Hollander (eds.) Genetic engineering of osmoregulation. Impact of plant productivity for food, chemicals and energy. Plenum Press, New York, USA.

Wegner, L.H. 2010. Oxygen transport in waterlogged plants, waterlogging signalling and tolerance in plants. p. 3-22. In Mancuso, S., and S. Shabala (eds.) Waterlogging signalling and tolerance in plants. Springer-Verlag, Berlin, Germany.

Zabalza, A., J.T. van Dongen, A. Froehlich, S.N. Oliver, B. Faix, K.J. Gupta, et al. 2009. Regulation of respiration and fermentation to control the plant internal oxygen concentration. Plant Physiology 149:1087-1098. 